\title{
The Group I Metabotropic Glutamate Receptor mGluR5 Is Required for Fear Memory Formation and Long-Term Potentiation in the Lateral Amygdala
}

\author{
Sarina M. Rodrigues, Elizabeth P. Bauer, Claudia R. Farb, Glenn E. Schafe, and Joseph E. LeDoux \\ W. M. Keck Foundation Laboratory of Neurobiology, Center for Neural Science, New York University, New York, \\ New York 10003
}

The group I metabotropic glutamate receptor subtype mGluR5 has been shown to play a key role in the modulation of synaptic plasticity. The present experiments examined the function of mGluR5 in the circuitry underlying Pavlovian fear conditioning using neuroanatomical, electrophysiological, and behavioral techniques. First, we show using immunocytochemical and tract-tracing methods that mGluR5 is localized to dendritic shafts and spines in the lateral nucleus of the amygdala (LA) and is postsynaptic to auditory thalamic inputs. In electrophysiological experiments, we show that long-term potentiation at thalamic input synapses to the LA is impaired by bath applica-

Metabotropic glutamate receptors (mGluRs) modulate neural activity via their linkage to various intracellular cascades (for review, see Nakanishi, 1992; Pin and Duvoisin, 1995; Anwyl, 1999). The Group I mGluRs, which consist of the subtypes mGluR1 and mGluR5, appear to be especially important for synaptic plasticity (Huber et al., 1998; Balschun et al., 1999; Kleppisch et al., 2001). Neuroanatomical, behavioral, and electrophysiological experiments have recently shown that the mGluR5 subtype, in particular, is critical for the associative strengthening of neural connections during learning (Lu et al., 1997; Jia et al., 1998; Riedel et al., 2000). The contribution of mGluR5 to synaptic plasticity and associative learning may be related to the fact that it has a mutual potentiative relationship with NMDA receptors (NMDARs) (Doherty et al., 1997; Alagarsamy et al., 1999, 2001). In addition, these two classes of glutamate receptors are linked via synaptic scaffolding proteins (Ehlers, 1999; Naisbitt et al., 1999; Tu et al., 1999). These factors allow the mGluR5 and NMDARs to work in tandem to regulate synaptic strength and flexibility (De Blasi et al., 2001).

mGluR5 is widely distributed in brain regions implicated in memory, such as the hippocampus (Romano et al., 1995; Balazs et al., 1997; Shigemoto et al., 1997). Transgenic mice lacking mGluR5 display a complete loss of the NMDAR-mediated component of long-term potentiation (LTP) in the CA1 region of the hippocampus (Lu et al., 1997; Jia et al., 1998) and show impairments in memory tasks, including the acquisition and use of spatial information in the Morris water maze (Lu et al., 1997),

Received Jan. 14, 2002; revised April 4, 2002; accepted April 8, 2002.

This research was supported in part by National Institute of Mental Health Grants R01 MH 46516, R37 MH 38774, and P50 MH 58911. This work was also supported by a grant from the W. M. Keck Foundation to New York University.

Correspondence should be addressed to Dr. Joseph E. LeDoux, Center for Neural Science, New York University, 4 Washington Place, Room 809, New York, NY 10003. E-mail: ledoux@cns.nyu.edu.

Copyright (C) 2002 Society for Neuroscience $\quad 0270-6474 / 02 / 225219-\bullet \$ 15.00 / 0$ tion of a specific mGluR5 antagonist, 2-methyl-6-(phenylethynyl)-pyridine (MPEP), in vitro. Finally, we show that intraamygdala administration of MPEP dose-dependently impairs the acquisition, but not expression or consolidation, of auditory and contextual fear conditioning. Collectively, the results of this study indicate that mGluR5 in the LA plays a crucial role in fear conditioning and in plasticity at synapses involved in fear conditioning.

Key words: mGluR5; fear conditioning; MPEP; LTP; amygdala; plasticity

that depend on NMDAR-mediated plasticity in CA1 (Morris et al., 1990; Tsien et al., 1996).

Consistent with the importance of mGluR5 in hippocampaldependent plasticity (Bortolotto et al., 1999), it has been shown that mGluR5 plays a role in contextual fear conditioning ( $\mathrm{Lu}$ et al., 1997; Riedel et al., 2000), a task that requires the hippocampus to form a representation of the context (Fanselow and Kim, 1994; Phillips and LeDoux, 1994; Maren and Holt, 2000). mGluR5 expression increases in the hippocampus during contextual fear conditioning (Riedel et al., 2000), and transgenic mice lacking mGluR5 are impaired in this task (Lu et al., 1997). However, contextual fear conditioning depends not only on the hippocampus, but also on the amygdala. The amygdala is believed to be crucial for the formation of the association between the conditioned stimulus (CS) and the unconditioned stimulus (US). Thus, in contextual fear conditioning, the amygdala creates the link between the hippocampal representation of the context and the aversive shock (US) (LeDoux, 2000).

The integration of the CS and US also occurs in the amygdala for cued fear conditioning, a task in which a discrete stimulus, such as a tone, is paired with the US. In auditory fear conditioning, the CS and US converge in the lateral nucleus of the amygdala (LA) (Romanski et al., 1993), and such convergence enhances the processing of the CS (Quirk et al., 1995; Rogan and LeDoux, 1995; Paré and Collins, 2000; Maren, 2001; Repa et al., 2001). Although systemic injection of the selective mGluR5 antagonist 2-methyl-6-(phenylethynyl)-pyridine (MPEP) blocks the acquisition of cued fear conditioning (Schulz et al., 2001), it is not known whether this effect is caused by the blockade of mGluR5 in the LA. However, given the importance of NMDARs in the LA to fear conditioning (Miserendino et al., 1990; Campeau et al., 1992; Fanselow and Kim, 1994; Gewirtz and Davis, 1997; Lee and Kim, 1998; Walker and Davis, 2000; Fendt, 2001; Rodrigues et al., 2001), and the interaction of mGluR5 with NMDARs in 
hippocampal plasticity, it seems likely that mGluR5 also plays a role in NMDAR-mediated fear conditioning in the LA.

In the present study, we therefore attempted to define the role of mGluR5 in fear conditioning circuits in the amygdala. First, we examined the distribution of mGluR5 in the LA at the level of both light and electron microscopy. Next, we administered MPEP to amygdala slices to evaluate the effects of mGluR5 antagonism on LTP in the LA in vitro. Finally, we infused MPEP into the LA in behavioral experiments to assess the role of mGluR5 in the acquisition, expression, and consolidation of conditioned fear. Collectively, the results of these studies provide a comprehensive view of the role of mGluR5 in the amygdala during fear conditioning.

\section{MATERIALS AND METHODS}

\section{Subjects}

Subjects were adult male Sprague Dawley rats (Hilltop Labs, Scottdale, PA). They were housed individually in plastic Nalgene cages and placed on a $12 \mathrm{hr}$ light/dark cycle. Food and water were provided ad libitum throughout the experiment. All procedures were in accordance with the National Institutes of Health Guide for the Care and Use of Experimental Animals and were approved by the New York University Animal Care and Use Committee.

\section{Anatomical studies}

Anterograde transport studies. Rats were anesthetized with a mixture of ketamine (Ketaset; $120 \mathrm{mg} / \mathrm{kg}$, i.p.), xylazine (Xyla-jet; $6.0 \mathrm{mg} / \mathrm{kg}$, i.p.), and medetomidine hydrochloride (Domitor; $0.5 \mathrm{mg} / \mathrm{kg}$, i.p.) and placed in a stereotaxic apparatus. Lysine-fixable biotinylated dextran-amine (BDA) conjugated to tetramethylrhodamine (Micro-ruby; Molecular Probes) was iontophoretically delivered, as described previously (Farb and LeDoux, 1997), to the medial geniculate body and posterior intralaminar nucleus (MGm/PIN) through glass micropipettes. The wound was closed, and a reversal agent, atipamezole (Antisedan; $1 \mathrm{mg} / \mathrm{kg}$, i.p.), and an analgesic, butorphanol tartrate (Torbugesic, $2 \mathrm{mg} / \mathrm{kg}$, i.p.), were administered. The animals were allowed to recover before being returned to the animal facility. The animals survived $14 \mathrm{~d}$ and were perfused with fixative.

Tissue fixation. Three fixation protocols were used as described previously (Farb et al., 1995). Because labeling was consistent across fixation conditions, the tissue analyzed for this study was fixed with acrolein to achieve optimal mGluR5 labeling while preserving ultrastructural morphology. Naïve and BDA-injected animals were anesthetized with pentobarbital $(120 \mathrm{mg} / \mathrm{kg})$ and transcardially perfused with heparinized $0.9 \%$ saline, $50 \mathrm{ml}$ of $3 \%$ acrolein mixed into $4 \%$ paraformaldehyde (PFA) dissolved in $0.1 \mathrm{M}$ phosphate buffer, and $450 \mathrm{ml}$ of $4 \%$ PFA. The brains were removed from the skull, blocked, and postfixed in 4\% PFA for $30 \mathrm{~min}$. Blocks containing the amygdala and thalamus (if BDA injected) were cut on a vibratome and sectioned at $40 \mu \mathrm{m}$. Tissue sections were treated with $1 \%$ sodium borohydride in phosphate buffer for $30 \mathrm{~min}$ and rinsed with $0.1 \mathrm{M}$ PBS, $\mathrm{pH}$. 7.4.

$B D A$ processing. Tissue sections designated for light microscopy and containing the MGm/PIN and amygdala were placed in an avidin-biotin horseradish peroxidase complex (ABC Elite Kit; Vector) solution containing $0.2 \%$ Triton X-100. Amygdala sections designated for electron microscopy were freeze-thawed (Farb and LeDoux, 1997) and placed in ABC solution without Triton X-100. All tissue sections were incubated overnight at room temperature, rinsed, reacted with $3,3^{\prime}$ diaminobenzidine tetrachloride (DAB; Sigma-Aldrich) and $0.003 \%$ $\mathrm{H}_{2} \mathrm{O}_{2}$, and rinsed with PBS. The tissue was then processed for mGluR5 immunoreactivity as described below.

Immunocytochemical labeling. Tissue sections containing the amygdala from naïve and BDA-injected animals were preincubated in PBS containing bovine serum albumin (BSA) for $30 \mathrm{~min}$, followed by overnight incubation at room temperature with rabbit polyclonal antisera directed against mGluR5 (1:250; Chemicon). The following day, the tissue was rinsed in PBS and incubated in goat anti-rabbit biotinylated IgG (Vector), $\mathrm{ABC}$ solution, and $\mathrm{DAB}$ and hydrogen peroxide. Primary and secondary antisera incubations included $1 \%$ BSA. All incubations were performed at room temperature with continuous agitation in PBS. Control experiments omitted either the primary antibody or substituted a mismatched secondary, e.g., anti-mouse $\mathrm{IgG}$ for the anti-rabbit IgG, and the tissue was reacted as described above. Controls for transport studies included analyzing naïve animals for mGluR5 immunoreactivity and examining the amygdala contralateral to the injection site for mGluR5 immunoreactivity.

Electron microscopic processing. Tissue sections designated for electron microscopy were processed as described previously (Farb and LeDoux, 1997). To facilitate analysis and detection of mGluR5 immunoreactivity, tissue was not counterstained with lead citrate.

Three vibratome sections from each brain were used for analysis. Neuronal and glial elements were classified according to the definitions of Peters et al. (1991) and as described previously (Farb and LeDoux, 1997). To determine the proportion of thalamic afferents that synapse onto mGluR5 targets, BDA-labeled terminals were photographed at a magnification of $10-25,000 \times$, and the target and its microenvironment were assessed. Only those micrographs containing labeled afferents and receptor labeling with a $27 \mu \mathrm{m}^{2}$ area were evaluated to avoid false negatives attributable to inadequate penetration of antisera.

\section{Slice electrophysiology}

Electrophysiological experiments in amygdala slices were conducted as described previously (Weisskopf et al., 1999; Bauer et al., 2002). Briefly, male Sprague Dawley rats (3-5 weeks old) were deeply anesthetized with halothane, and the brain was removed rapidly and transferred to ice-cold artificial CSF (ACSF) containing (in $\mathrm{mM}$ ): $115 \mathrm{NaCl}, 3.3 \mathrm{KCl}, 1 \mathrm{MgSO}_{4}$, $2 \mathrm{CaCl}_{2}, 25.5 \mathrm{NaHCO}_{3}, 1.2 \mathrm{NaH}_{2} \mathrm{PO}_{4}, 5$ lactic acid, and 25 glucose, and equilibrated with $95 \% \mathrm{O}_{2}, 5 \% \mathrm{CO}_{2}$. Coronal slices $(400 \mu \mathrm{m}$ thick $)$ containing the amygdala were cut and recovered in a holding chamber at $32-34^{\circ} \mathrm{C}$ for $30 \mathrm{~min}$ and were then allowed to return to room temperature for at least another $30 \mathrm{~min}$ before recording. An upright microscope equipped with infrared differential interference contrast optics (Olympus) was used to perform whole-cell patch recordings under visual guidance. Electrodes were filled with (in $\mathrm{mm}$ ): $130 \mathrm{~K}$-Gluconate, 0.6 EGTA, $2 \mathrm{MgCl}_{2}, 5 \mathrm{KCl}, 10 \mathrm{HEPES}, 2 \mathrm{Mg}$-ATP, and $0.3 \mathrm{Na}_{3}$-GTP. The electrodes typically had resistances of $4-8 \mathrm{M} \Omega$. All cells were allowed to remain at their resting potentials.

Stimuli (150 $\mu$ sec duration) were delivered through bipolar stainless steel electrodes placed in the ventral striatum, just medial to the LA. This stimulating protocol activates fibers that originate, at least in part, in the auditory thalamus (Weisskopf et al., 1999). Confounds introduced by polysynaptic responses were controlled for by keeping the stimulation intensity at a minimum to produce a reliable EPSP without also recruiting polysynaptic responses or spiking, by computing percentage increase of the initial slope of the EPSP and by excluding any data that demonstrated a change in EPSP latency after LTP induction. Baseline responses were monitored at $0.1 \mathrm{~Hz}$. After stabilization of baseline responses, LTP was induced by a tetanus protocol that consisted of a $30 \mathrm{~Hz}$ tetanus (100 stimuli, given twice with a $20 \mathrm{sec}$ interval). For each cell, the stimulation intensity for LTP induction was the same as that used to elicit baseline EPSPs. Only cells with membrane potentials greater than -60 $\mathrm{mV}$ and action potentials that exceeded $0 \mathrm{mV}$ were included in this study.

Picrotoxin $(75 \mu \mathrm{M})$ was included in the bath in all experiments to block fast GABAergic transmission but was not observed to produce epileptiform bursting in the amygdala. MPEP was made up in 100\% DMSO stock solution and diluted 1000 times into the superfusing ACSF, yielding a final concentration of $40 \mu \mathrm{M}$ MPEP. MPEP was washed out 10-15 min after LTP induction. In all experiments, the slope of the EPSP was measured, and LTP for each time point was expressed as a percentage of the preinduction baseline.

For the analysis of LTP, the values for the initial slope of the EPSP recorded during the last $15 \mathrm{~min}$ of the recording session (minutes 35-50) were averaged into a single score for each cell. The amount of potentiation was analyzed by comparing these values with the preinduction values and testing with a paired Student's $t$ test. Comparison of the amount of potentiation between groups (vehicle vs drug) was tested with a two-tailed, independent Student's $t$ test. To analyze the effects of MPEP on transmission at thalamic input synapses, we compared the initial slope of the EPSP at minutes 20-30 (last $10 \mathrm{~min}$ ) and compared it with the last $10 \mathrm{~min}$ of baseline using a paired (correlated samples) Student's $t$ test.

\section{Behavioral procedures}

Behavioral procedures were conducted as described previously (Rodrigues et al., 2001). Rats were anesthetized with a mixture of ketamine (100 mg/kg, i.p.), xylazine (6.0 mg/kg, i.p.), and medetomidine (0.5 $\mathrm{mg} / \mathrm{kg}$, i.p.) and implanted bilaterally with $7 \mathrm{~mm}, 22$ gauge stainless steel 
guide cannulas aimed at the LA (Plastics One). The guide cannulas were fixed to screws in the skull with dental cement and a dummy cannula, which extended $0.5 \mathrm{~mm}$ from the guide, was inserted into each guide to prevent clogging. After surgery, rats were administered butorphanol tartrate $(2.0 \mathrm{mg} / \mathrm{kg}$, i.p.) and atipamezole $(1.0 \mathrm{mg} / \mathrm{kg}$, i.p.) for analgesia and reversal of the anesthetic. Rats were given at least $5 \mathrm{~d}$ to recover before experimental procedures.

Rats were divided into different groups to test the effects of intra-LA inf usion of MPEP on the acquisition, expression, and consolidation of fear conditioning. For each inf usion, a total volume of $0.5 \mu \mathrm{l}$ of an MPEP solution or an equivalent amount of saline vehicle $(0.9 \%)$ was infused into each amygdala at a rate of $0.25 \mu \mathrm{l} / \mathrm{min}$ using 28 gauge infusion cannulas that extended $1.0 \mathrm{~mm}$ from the base of the guide. After the infusion, the cannulas were left in place for an additional $1 \mathrm{~min}$ to allow the solution to diffuse away from the cannula tip. The dummy cannulas were then replaced, and the rat was returned to its home cage. Infusions occurred 20-30 min before conditioning and testing for the acquisition and expression experiments, and 20-30 min before conditioning and immediately after conditioning for the post-training infusion experiment.

On the day before conditioning, rats were habituated to the training and testing chambers and to dummy cannula removal for a minimum of 10-15 min. The next day, rats were trained with the presentation of five pairings of a $20 \mathrm{sec}$ tone $\mathrm{CS}(5 \mathrm{kHz}, 75 \mathrm{~dB})$ that coterminated with a foot shock US ( $0.5 \mathrm{sec}, 0.5 \mathrm{~mA})$. The intertrial interval (ITI) varied randomly between 90 and $120 \mathrm{sec}$.

Fear responses conditioned to the tone $\mathrm{CS}$ and the conditioning apparatus (context) were tested separately. Responses conditioned to the tone CS were measured in a novel test chamber [for details, see Rodrigues et al. (2001)]. A test of short-term memory (STM) and long-term memory (LTM) was performed 1 and $24 \mathrm{hr}$ after fear conditioning, respectively. For both tests, rats were exposed to three test tones $(20 \mathrm{sec}$, $5 \mathrm{kHz}, 75 \mathrm{~dB}$; ITI $=100 \mathrm{sec}$ ) after a brief acclimation period to the test chamber. For the context test, rats were placed in the conditioning chamber and allowed to explore for $5 \mathrm{~min}$, after which the duration of freezing was measured every other $30 \mathrm{sec}$ for an additional $5 \mathrm{~min}$. Testing for tone and contextual memory was approximately the same total length (10 $\mathrm{min})$.

To verify injector tip location, rats were anesthetized with an overdose of chloral hydrate $(600 \mathrm{mg} / \mathrm{kg}$, i.p.) and perfused transcardially with $10 \%$ buffered formalin. The brains were postfixed in $30 \%$ sucrose in $10 \%$ buffered formalin and subsequently blocked, sectioned on a cryostat or microtome at $50 \mu \mathrm{m}$, and stained for Nissl with thionin. Sections were coverslipped with Permount and examined under light microscopy for injector tip penetration into the amygdala.

\section{RESULTS}

\section{mGluR5 is localized to dendritic shafts and spines in the LA and is postsynaptic to auditory thalamic afferents.}

Previous studies have shown that mGluR5 is widely distributed in brain regions implicated in certain forms of memory, including the hippocampus and cortex (Romano et al., 1995; Shigemoto et al., 1997). In the hippocampus, it is mostly localized in postsynaptic densities and dendritic spines but is also expressed in presynaptic terminals and on astrocytes (Romano et al., 1995; Balazs et al., 1997). However, no study to date has examined the ultrastructural localization of mGluR5 in the amygdala. To this end, we first used light microscopy to verify the presence and distribution of mGluR5 in the LA. We then used electron microscopy to determine the ultrastructural localization of mGluR5 and its relationship to auditory thalamic afferents.

\section{Light microscopy}

Figure $1 A$ shows the distribution of mGluR5 within the LA. The amount of mGluR5 immunoreactivity in the dorsal division of the lateral nucleus is similar to staining in the ventrolateral division but less robust than the ventromedial division. Immunolabeling in the LA was not as robust as in adjacent regions, e.g., the amgydala-striatal transition region, or the central nucleus of the amygdala. However, higher-power Nomarski optics $(40 \times)$
(Fig. $1 A$, inset) reveal the presence of many labeled cells, their proximal dendrites, and punctate processes scattered throughout the amygdala. Frequently, the labeled cell bodies contained puncta dispersed throughout the cytoplasm. In contrast to the LA, where only the proximal dendrites of labeled cells were seen, the distal dendrites of cells in the basal nucleus of the amygdala and endorpiriform cortex were observed.

\section{Electron microscopy}

Consistent with the findings of previous studies (Farb and LeDoux, 1997), BDA reaction product was confined to axon terminals; DAB reaction product in dendritic or somatic elements was not seen. BDA labeling was dense and homogeneously distributed throughout the terminal, and most of the identifiable afferents formed asymmetric synapses onto small distal dendritic processes.

The intracellular distribution of mGluR5 immunoreactivity within the LA was comparable to other brain regions (Romano et al., 1995; Negyessy et al., 1997; Hubert et al., 2001). As in the hippocampus and cortex, mGluR5 in the LA is primarily localized to postsynaptic regions near the synapse. mGluR5 labeling was seen along the intracellular surface of somata, dendrites, dendritic spines, and glia. When dendritic labeling was extensive, the peroxidase product rimmed the microtubules and was seen throughout the dendrite. However, frequently only a patch of immunoreactivity that corresponded to the synaptic or spinous portion of a dendrite was seen (Fig. $1 B, C$ ). The immunoperoxidase was often observed to reside on the extrasynaptic portions of the postsynaptic density (PSD) (Fig. 1D). Axon terminals were rarely labeled, and when labeled, immunoperoxidase appeared in small, discrete patches. One hundred twenty-one BDA-labeled terminals were counted, and these terminals formed 126 asymmetric synapses. Most (124 of 126; 98\%) of these synapses occurred on small dendrites or dendritic spines. Fifty-six percent (71 of 126) of these synapses occurred on dendritic processes that were immunoreactive for mGluR5.

\section{In vitro application of MPEP to amygdala slices impairs NMDAR-dependent long-term potentiation in the LA}

In the next series of experiments, we used an in vitro slice preparation to induce LTP in the LA to examine the impact of mGluR5 blockade on synaptic plasticity in the LA. In these experiments, we measured LTP at "thalamic" input synapses to the LA by placing stimulating electrodes in the ventral striatum, which contains, in part, fibers that originate in the auditory thalamus and terminate in LA (LeDoux et al., 1990) (Fig. 2A). Given the role of NMDARs in fear conditioning (Miserendino et al., 1990; Campeau et al., 1992; Fanselow and Kim, 1994; Gewirtz and Davis, 1997; Lee and Kim, 1998; Walker and Davis, 2000; Fendt, 2001; Rodrigues et al., 2001) and the contribution of mGluR5 to NMDAR-mediated plasticity (Anwyl, 1999), we chose to use a $30 \mathrm{~Hz}$ tetanus, an LTP induction protocol that has recently been shown to be NMDAR dependent (Blair et al., 2001; Bauer et al., 2002).

Neurons in the LA can be classified into two main types. Most are spiny with a pyramidal morphology, have relatively broad action potentials, and show marked spike-frequency adaptation (Rainnie et al., 1991; McDonald 1992; Paré et al., 1995). A smaller fraction of cells are aspiny and have relatively higher resting membrane potentials, faster action potentials, and no spike frequency adaptation (Paré et al., 1995; Mahanty and Sah, 1998). All of the data in this study were obtained from putative 

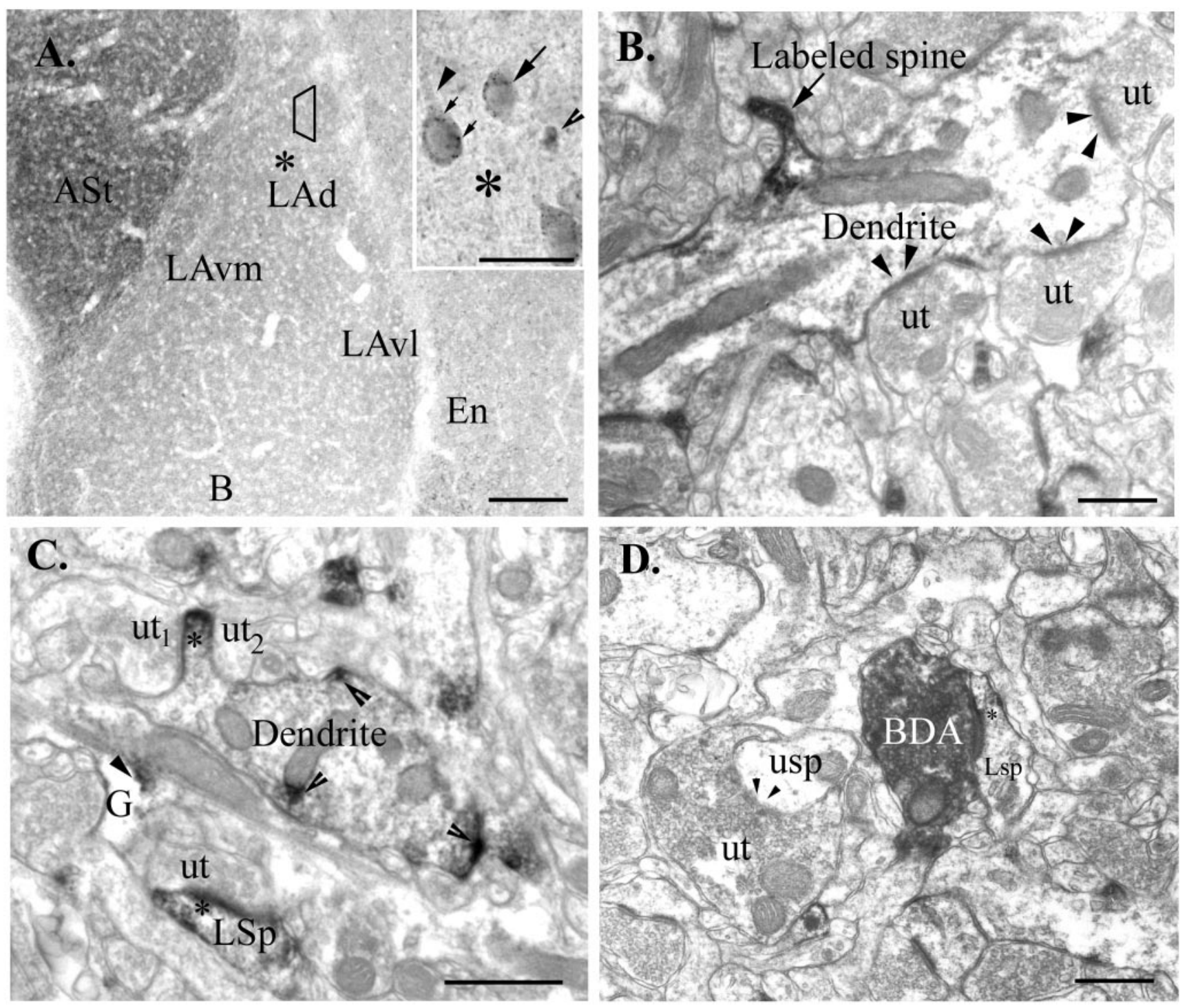

Figure 1. Light and electron micrographs illustrate mGluR5 immunolabel in the amygdala. $A$, Low-power $(4 \times)$ photomicrograph shows the distribution of mGluR5 immunoreactivity in the amygdala and adjacent regions. The labeling in the dorsal division of the lateral nucleus $(L A d)$ is comparable to staining in the ventrolateral division $(L A v l)$ but is less robust than the ventromedial division $(L A v m)$ of the lateral nucleus or in the amygdala-striatal transition area $(A S t)$. The basal nucleus of the amygdala $(B)$ and the endorpiriform cortex $(E n)$ are also shown. The trapezoid corresponds to the region sampled for electron microscopic analysis, and the asterisk corresponds to the region shown at higher magnification in the inset. Inset, Higher-power Nomarski optics $(40 \times)$ reveal labeled cell bodies (arrow) and cytoplasmic puncta (small arrows). Proximal dendritic processes (arrowhead) and puncta (open arrowhead) are also seen within the neuropil. The asterisk corresponds to the region shown in the low-magnification panel. $B$, Electron micrograph shows immunolabel restricted to the spinous portion (Labeled spine) of a large dendrite. Arrowheads indicate the unlabeled synapses made by unlabeled terminals $(u t)$. $C$, Unlabeled terminals $\left(u t_{1}\right.$ and $\left.u t_{2}\right)$ appear to contact the spinous portion of the dendrite, which is immunolabeled $(*)$. mGluR5 immunolabel (open arrowheads) is also seen in discreet patches within a dendrite. An immunolabeled glial process ( $G$; arrowhead indicates immunolabel), a labeled spine $(L S p)$, and an unlabeled terminal are also shown. $D$, A labeled spine $(L S p)$ receives a synapse from a BDA-labeled terminal. Asterisk indicates the presence of immunolabel. An unlabeled terminal (ut), an unlabeled spine (usp), and an unlabeled synapse (arrowheads) are shown for comparison. Scale bars: $A, 150 \mu \mathrm{m}$; inset, $25 \mu \mathrm{m} ; B-D, 500 \mathrm{~nm}$.

excitatory cells in the LA, on the basis of these electrophysiological properties. The average $( \pm \mathrm{SD})$ resting membrane potential, input resistance, and membrane time constant for the 30 recorded cells were $-67.1 \pm 3.0 \mathrm{mV}, 160 \pm 34.5 \mathrm{M} \Omega$, and $18.3 \pm 5.3 \mathrm{msec}$, respectively.

The results of the in vitro experiments can be seen in Figure 2. Bath application of $40 \mu \mathrm{M}$ MPEP blocked the induction of LTP induced by the tetanus (Fig. $2 B$ ). The control group showed $143 \pm 10.2 \%$ potentiation of baseline, which was significantly different from baseline $\left(t_{(8)}=4.32 ; p<0.05 ; n=9\right)$. The MPEP group showed $100 \pm 6.2 \%$ potentiation, which was not significantly different from baseline $(p>0.05 ; n=8)$ but was significantly different from vehicle controls $\left(t_{(15)}=3.75 ; p<0.05\right)$.

To determine whether MPEP affects baseline synaptic transmission in the LA, we next examined the effects of $40 \mu \mathrm{M}$ MPEP on the initial slope and maximum amplitude of EPSPs induced by thalamic stimulation (Fig. 2C). MPEP was added to the superfusing ACSF after a baseline period of at least $10 \mathrm{~min}$. An analysis of the size of the initial slope of the EPSPs 15-20 min after MPEP application showed no significant effects of the drug 

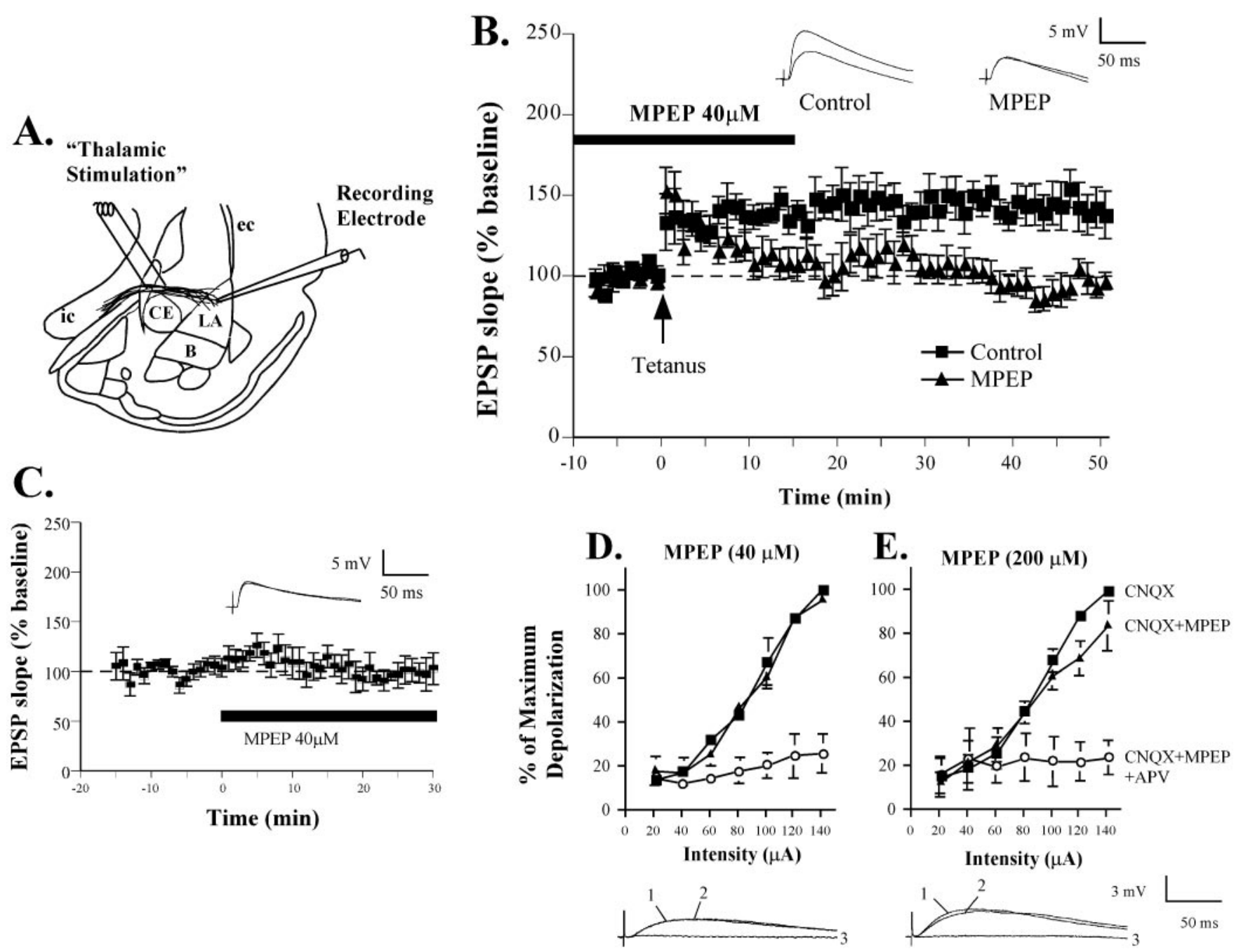

Figure 2. Impaired amygdala LTP by MPEP. $A$, Schematic of the amygdala slice preparation, showing placement of stimulating and recording electrodes. Afferent fibers from the auditory thalamus enter the LA medially, coursing through the ventral part of the striatum just above the central nucleus. Recordings were made just below the site of termination of auditory thalamic fibers terminating in the dorsal portion of the LA. IC, Internal capsule; $O T$, optic tract; $E C$, external capsule. $B$, Mean $( \pm \mathrm{SE})$ percentage EPSP slope (relative to baseline) in cells treated with vehicle (n $=9$; $\mathbf{\square})$ or $40 \mu \mathrm{M}$ MPEP $(\mathrm{n}=8 ; \boldsymbol{\Lambda})$. Traces from an individual experiment before and 50 min after tetanic stimulation are shown in the inset. $C$, Mean $( \pm \mathrm{SE})$ percentage EPSP slope (\% of baseline) in cells $(\mathrm{n}=6)$ before and after treatment with MPEP $(40 \mu \mathrm{M}$; solid bar). Traces from an individual experiment before and 25 min after application of MPEP are shown in the inset. $D$, Percentage maximum depolarization of the NMDAR component of the EPSP across a range of stimulation intensities (20-140 $\mu \mathrm{A})$ after bath application of $10 \mu \mathrm{M} \mathrm{CNQX}$ alone $(\mathrm{n}=3$; $\mathbf{\square})$, CNQX and $40 \mu \mathrm{M}$ MPEP $(\mathbf{\Delta})$, or CNQX, MPEP, and $50 \mu \mathrm{M} \mathrm{APV}(\bigcirc)$. Representative traces evoked by $120 \mu \mathrm{A}$ stimulation are shown superimposed below $(1=\mathrm{CNQX}, 2=\mathrm{CNQX}$ and $\mathrm{MPEP}$, $3=\mathrm{CNQX}, \mathrm{MPEP}$, and APV). E, Percentage maximum depolarization of the NMDAR component of the EPSP across a range of stimulation intensities $(20-140 \mu \mathrm{A})$ after bath application of $10 \mu \mathrm{M}$ CNQX alone $(\mathrm{n}=4$; $\mathbf{\square})$, CNQX and $200 \mu \mathrm{M}$ MPEP $(\mathbf{\Delta})$, or CNQX, MPEP, and 50 $\mu \mathrm{M}$ APV (O). Representative traces evoked by $120 \mu \mathrm{A}$ stimulation are shown below the figure.

$(98.1 \pm 10.2 \% ; p>0.05 ; n=6)$. Thus, blockade of mGluR5 impairs NMDAR-dependent LTP at thalamic input synapses in the LA, without affecting routine synaptic transmission.

\section{MPEP does not act as a direct antagonist of the NMDA receptor at the concentrations that impair NMDAR-dependent LTP in the LA}

Recent studies have shown that MPEP at concentrations as low as $10 \mu \mathrm{M}$ can directly decrease NMDAR currents in cultured cortical neurons (O'Leary et al., 2000). Because we used $40 \mu \mathrm{M}$ MPEP in our in vitro LTP experiments, it is thus not possible to conclude unambiguously that the LTP impairment that we observed (Fig. $2 B$ ) is caused exclusively by blockade of mGluR5 receptors. However, the concentration used in cultured neurons may or may not be relevant to our preparation. Furthermore, other studies have found that concentrations of MPEP up to $100 \mu \mathrm{M}$ have no significant effect on NMDAR currents (Gasparini et al., 1999). The key question, however, is whether $40 \mu \mathrm{M}$ MPEP has an effect on NMDAR currents in our specific preparation. To test this, we examined the effects of MPEP on the NMDAR component of synaptic potentials in LA neurons. Previous studies have shown that in the presence of the AMPA receptor blocker CNQX, there is still a residual excitatory response elicited in LA neurons by synaptic stimulation that is sensitive to the NMDAR antagonist, DL-2-amino-5-phosphonovaleric acid (APV) (Weisskopf and LeDoux, 1999). Thus, we measured the amplitude of this residual synaptic response in the presence of CNQX $(10 \mu \mathrm{M})$ across a range of stimulation intensities $(20-140 \mu \mathrm{A})$ before and after bath application of either 40 or $200 \mu \mathrm{M}$ MPEP, or MPEP and 50 
$\mu \mathrm{M}$ APV. For all experiments, CNQX was washed on first, followed by MPEP (40 or $200 \mu \mathrm{M}$ ), and finally by APV. Ten minutes passed between each drug application and the generation of the input-output $(\mathrm{I} / \mathrm{O})$ curves. For each cell, data were expressed as the percentage of the maximum depolarization, which was typically evoked by the $140 \mu \mathrm{A}$ stimulation intensity in CNQX alone. For analysis we compared the slope of each I/O curve, as well as the X-intercept at half of the maximum intensity.

Application of $40 \mu \mathrm{M}$ MPEP had no effect on the slope of the I/O curve (Fig. $2 D)(\mathrm{CNQX}=0.76 \pm 0.03$; CNQX $+40 \mu \mathrm{M}$ $\mathrm{MPEP}=0.72 \pm 0.07 ; p>0.05 ; n=3)$. The $\mathrm{X}$-intercept was also not affected $(\mathrm{CNQX}=76.05 \pm 1.28$; CNQX $+40 \mu \mathrm{M} \mathrm{MPEP}=$ $76.02 \pm 5.2 ; p>0.05)$. Application of APV, however, did significantly affect the slope of the I/O curve $(\mathrm{CNQX}+40 \mathrm{~mm} \mathrm{MPEP}+$ $50 \mathrm{~mm}$ APV $\left.=0.127 \pm 0.07 ; t_{(2)}=8.20 ; p<0.05\right)$.

At the higher concentration $(200 \mu \mathrm{M})$, MPEP was observed to have a small yet significant effect on the slope of the I/O curve (Fig. $2 E)(\mathrm{CNQX}=0.87 \pm 0.08 ; \mathrm{CNQX}+200 \mu \mathrm{M} \mathrm{MPEP}=$ $\left.0.59 \pm 0.11 ; t_{(3)}=3.31 ; p<0.05 ; n=4\right)$. There was still a significant difference, however, between the MPEP and APV curves $(\mathrm{CNQX}+200 \mu \mathrm{M} \mathrm{MPEP}+50 \mu \mathrm{M}$ APV $=0.03 \pm 0.03$; $\left.t_{(3)}=5.49 ; p<0.05\right)$. Thus, at very high concentrations, the NMDAR component of the EPSP in the LA appears to be modestly affected by MPEP. However, because there is no effect at the concentration that we used in our LTP experiments (40 $\mu \mathrm{M})$, it cannot be argued that the impairment that we have observed in our LTP experiments is caused by direct blockade of NMDARs.

\section{Intra-LA infusion of MPEP dose-dependently impairs acquisition, but not expression, of fear conditioning}

Previous studies have shown that systemic administration of MPEP impairs Pavlovian fear conditioning, as measured with the fear-potentiated startle paradigm (Schulz et al., 2001). In the present experiments, we examined the role of mGluRs in the LA in fear conditioning to contextual and auditory stimuli. In the initial series of experiments, rats were infused with vehicle or one of two doses of MPEP ( 0.15 or $1.5 \mu \mathrm{g}$ per side) before training and tested for both STM (at $1 \mathrm{hr}$ ) and LTM (at $24 \mathrm{hr}$ ) of auditory and contextual fear conditioning. In subsequent experiments, rats were infused with the highest dose of MPEP (1.5 $\mu \mathrm{g}$ per side) before testing to examine the effect of MPEP on fear expression. In each experiment, freezing scores across trials did not significantly differ and were therefore averaged for each rat into a single score. Scores were then expressed as a percentage of total CS presentation or observation time. All data were analyzed using ANOVA and Duncan's multiple range post hoc $t$ tests.

\section{Pretraining infusions}

MPEP infusions before conditioning produced a dose-dependent impairment in freezing for both tone and contextual STM at $1 \mathrm{hr}$ after conditioning (Fig. 3A). The ANOVA for tone memory scores showed a significant effect for group $\left(F_{(2,21)}=203.6 ; p<\right.$ 0.01 ), and post hoc $t$ tests showed that the two MPEP groups differed from the vehicle group $(p<0.01)$. The STM data in the context test exhibited a similar pattern. The ANOVA revealed a significant effect for group $\left(F_{(2,21)}=35.32 ; p<0.01\right)$, and post hoc $t$ tests showed that the low and high doses of MPEP produced a significant decrease in freezing behavior $(p<0.01)$ compared with vehicle controls. Furthermore, the high-dose group froze significantly less than the low-dose group $(p<0.05)$, suggesting a dose-dependent effect of MPEP in the LA.
These differences were also evident in the LTM tests performed $24 \mathrm{hr}$ after conditioning in which a dose-dependent impairment in auditory and contextual fear was found. The ANOVA for tone LTM freezing scores displayed a significant effect for group $\left(F_{(2,21)}=40.28 ; p<0.01\right)$, and, compared with controls, post hoc $t$ tests showed that both doses of MPEP produced an impairment in freezing $(p<0.01)$. Likewise, the ANOVA for contextual LTM showed a significant effect for group $\left(F_{(2,21)}=11.20 ; p<0.01\right)$, and $t$ tests showed that both doses of MPEP caused a deficit in contextual fear conditioning $(p<0.05)$. As with STM, a comparison of the LTM freezing scores for the low- and high-dose groups revealed a dosedependent effect of MPEP $(p<0.05)$. (Fig. 3A, bottom).

\section{Pretesting infusions}

In contrast to pretraining infusions, intra-amygdala infusions of MPEP before testing did not produce a significant effect in freezing for either tone or contextual conditioning (Fig. 3B) at either 1 or $24 \mathrm{hr}$ after training. Animals that received the highest dose of MPEP expressed similar levels of freezing to controls in the tone and context tests. The ANOVAs for tone and context STM and LTM showed no significant effects of this drug on performance $(p>0.05)$ (Fig. $3 B)$. Thus, MPEP appears to affect acquisition, but not expression, of contextual and auditory fear conditioning.

\section{Immediate post-training intra-LA infusion of MPEP has no effect on the consolidation of fear conditioning}

In the studies described above, pretraining inf usions of MPEP led to a deficit of STM and LTM of both tone and contextual fear conditioning. This impairment could be attributable to a failure to learn during acquisition or a failure to consolidate learning in the time after training (McGaugh, 2000). To distinguish between these alternatives, we performed immediate post-training infusions of MPEP after conditioning. In this experiment, rats received vehicle before training and either vehicle or the highest dose of MPEP (1.5 $\mu \mathrm{g}$ per side) immediately after training.

The results of the post-training infusions can be viewed in Figure 4. In contrast to the findings of the previous experiments in which rats received pretraining infusion of MPEP, posttraining infusions had no significant effect on retention of tone and context STM and LTM tests $(p>0.05)$. Thus, the effects of MPEP appear to be specific to the acquisition phase of fear conditioning.

\section{Histology}

Cannula placements for the intra-amygdala infusions are shown in Figure 5. Figure $5 A$ shows the cannula placements for rats that received MPEP infusions before training. Figure $5 B$ shows the cannula placements for rats that received MPEP infusions before testing. Finally, Figure $5 C$ shows cannula placements for rats that received MPEP immediately after training. Cannula injector tips were observed throughout the rostrocaudal extent of the LA, and only rats with cannula tips at or within the boundaries of the LA were included in the data analysis.

\section{DISCUSSION}

The family of mGluRs is classified into three different groups (groups I-III) on the basis of sequence similarities, signal transduction systems, and pharmacological profiles (Schoepp and Conn, 1993; Anwyl, 1999). Group I mGluRs have been shown to be especially important in synaptic plasticity in various experimental paradigms (Huber et al., 1998; Balschun et al., 1999; 


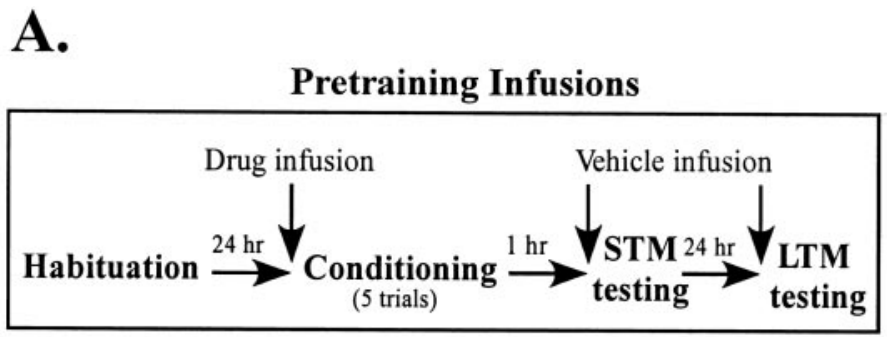

TONE MEMORY

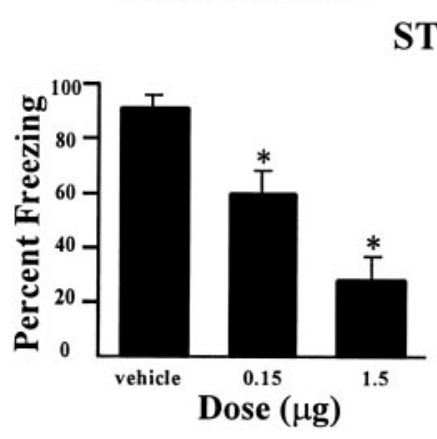

CONTEXTUAL MEMORY

STM

LTM

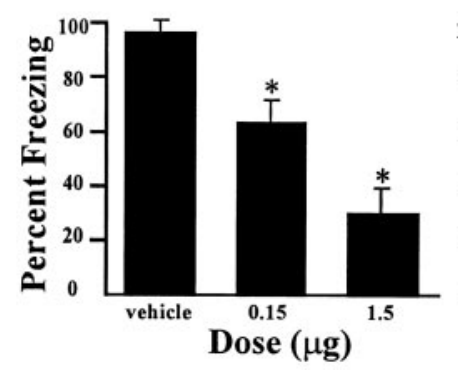

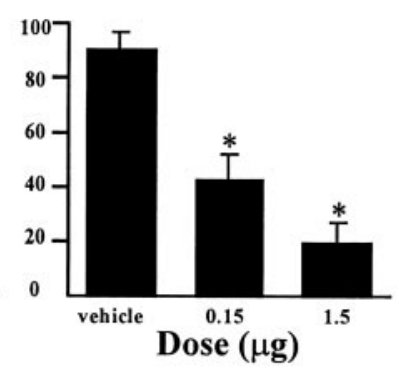

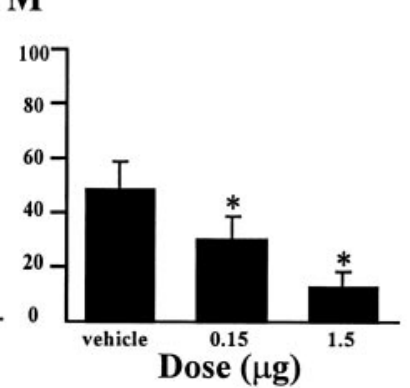

B.

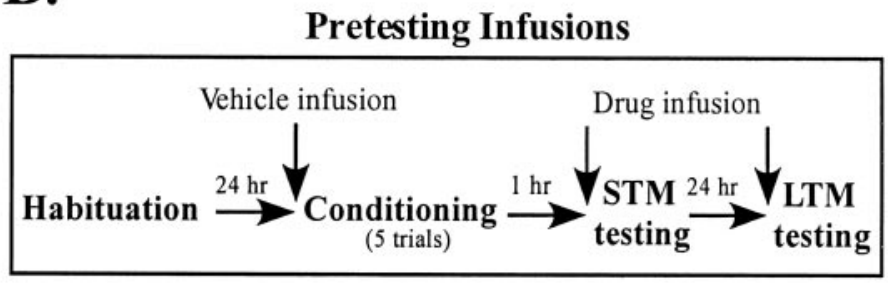

TONE MEMORY

CONTEXTUAL MEMORY

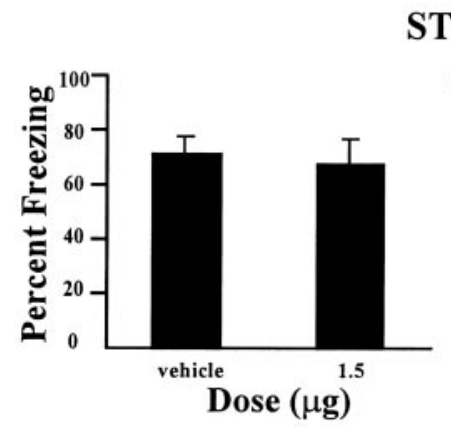

STM

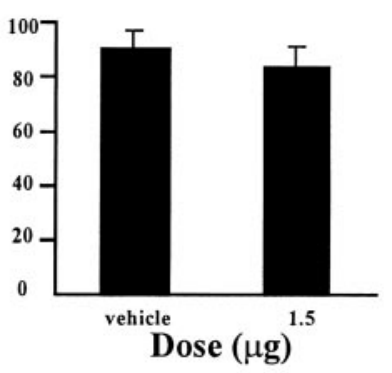

LTM
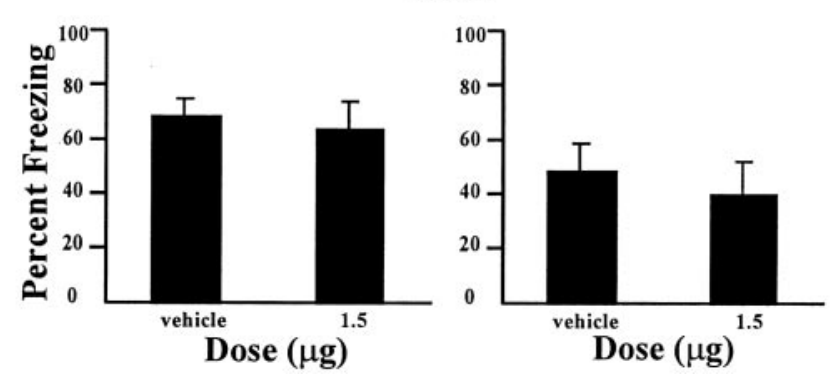

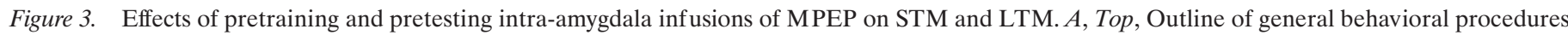

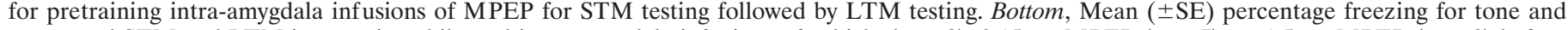

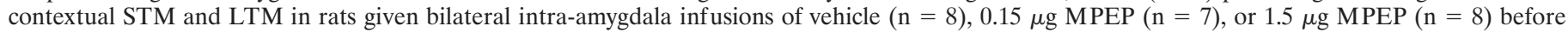

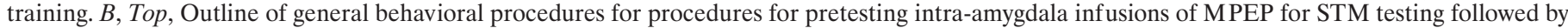

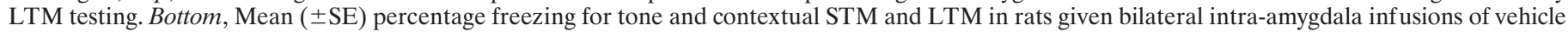
$(\mathrm{n}=8)$ or $1.5 \mu \mathrm{g}$ MPEP $(\mathrm{n}=8)$ before testing.

Kleppisch et al., 2001). Several studies have determined that group I mGluRs are vital for learning and LTP, using agents that target both mGluR1 and mGluR5 subtypes (Bashir et al., 1993; Wilsch et al., 1998; Balschun et al., 1999; Bortolotto et al., 1999; De Blasi et al., 2001). However, it is now possible to more specifically address the precise role of mGluR5 because of the availability of the new subtype-specific mGluR5 antagonist, MPEP. In the present study, we used neuroanatomical, electrophysiological, and behavioral methods to examine the role of mGluR5 in the amygdala. We focused on the LA, the sensory gateway into the amygdala and a critical site of plasticity in fear conditioning (for review, see LeDoux, 2000).

Our neuroanatomical analyses revealed that mGluR5 is predominantly located in postsynaptic structures in the LA. More than half of the counted BDA-labeled thalamic afferents from the $\mathrm{MGm} / \mathrm{PIN}$ formed synapses on mGluR5-immunoreactive dendrites and dendritic spines of LA neurons, indicating that this receptor is in a key position to modulate auditory information that arrives to the LA. This proportion of labeling is similar to that found for functional NMDARs in LA spines (Farb and LeDoux, 1997). In addition, a large fraction of mGluR5 was postsynaptic to unlabeled afferents, suggesting that this receptor may also be involved in the processing of cortical, intraamygdalar, or other sensory information. mGluR 5 was very rarely seen in terminals, suggesting that its role in the LA is primarily postsynaptic.

The postsynaptic localization of mGluR5 is consistent with the findings of a number of studies that have shown that mGluR5 interacts with other glutamate receptors, especially NMDARs (Naisbitt et al., 1999). For example, the group I agonists produce a potentiation of NMDA currents (Aniksztejn et al., 1991; Fitzjohn et al., 1996; Yu et al., 1997; Pisani et al., 2001) that is inhibited by MPEP (Mannaioni et al., 2001) and absent in mGluR5-deficient mice (Pisani et al., 2001). NMDARs appear to potentiate mGluR5-mediated responses, as well, by reversing desensitization of mGluR5 (Alagarsamy et al., 1999, 2001). Thus, mGluR5 and NMDARs seem to be involved in a reciprocal positive feedback relationship that has important implications for the modulation of synaptic plasticity (De Blasi et al., 2001). MPEP has also been shown to reduce NMDA-evoked whole-cell current and decrease the duration of opening of NMDARs recorded in the outside-out patch configuration in cultured rat 


\section{Posttraining Infusions}

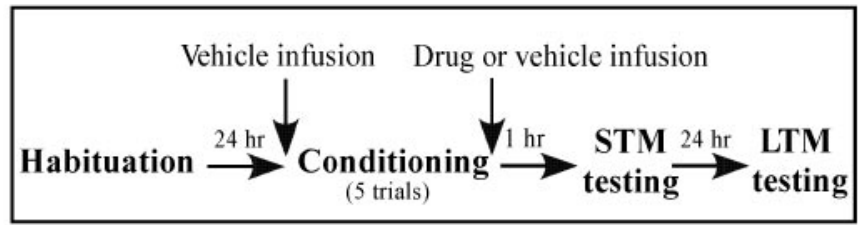

TONE MEMORY CONTEXTUAL MEMORY

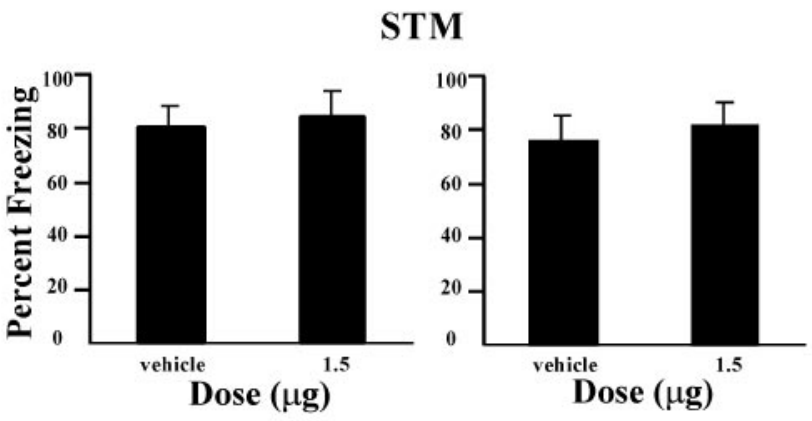

LTM
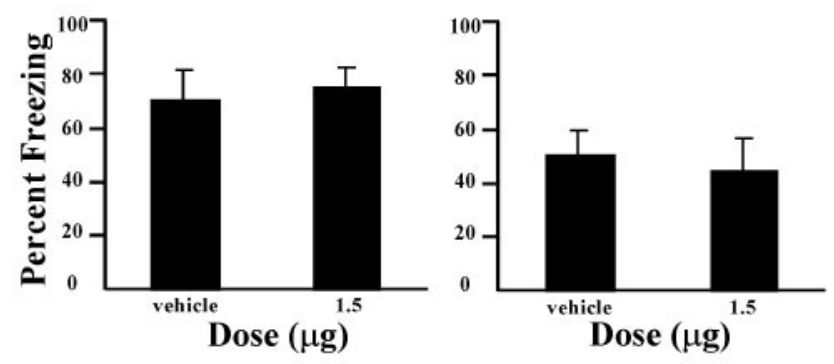

Figure 4. Effects of immediate post-training intra-amygdala infusions of MPEP on the consolidation of STM and LTM. Top, Outline of general behavioral procedures for post-training intra-amygdala infusions of MPEP for STM testing followed by LTM testing. Bottom, Mean ( \pm SE) percentage freezing for tone and contextual STM and LTM in rats given bilateral intra-amygdala inf usions of vehicle $(\mathrm{n}=7)$ or $1.5 \mu \mathrm{g} \operatorname{MPEP}(\mathrm{n}=$ 8) immediately after training.

cortical neurons (O’Leary et al., 2000). However, recordings from Xenopus oocytes expressing human NMDARs suggest that MPEP has no significant effect on NMDARs alone (Gasparini et al., 1999). Furthermore, MPEP reduces neural responses in the thalamus to a selective mGluR5 agonist, compared with those evoked by NMDA, indicating that MPEP is a selective mGluR5 antagonist in vivo (Salt and Binns, 2000). Together with our observation that MPEP had no significant effect on the NMDAR component of the EPSP in LA neurons at concentrations that effectively impair LTP, these findings collectively suggest that the effect of MPEP on NMDAR-mediated plasticity is not caused by direct antagonism of NMDARs. Rather, the findings are consistent with the idea that mGluR5 modulates the normal function of the NMDAR and plays a role in setting the tone of NMDARmediated activity (Alagarsamy et al., 1999).

Recent studies have shed light on how mGluR5 may communicate with NMDARs via physical interactions with various scaffolding proteins. For example, it has been shown that Homer proteins, which are rapidly and transiently induced by stimuli that induce LTP (Brakeman et al., 1997; Kato et al., 1997), are involved in the targeting of mGluR5 to synaptic sites (Ango et al., 2000). Homer proteins have been shown to bind with Shank proteins, which function as part of the NMDAR-associated PSD-95 complex (Naisbitt et al., 1999). The Homer-Shank interaction has been proposed to function by localizing mGluRs in proximity to NMDARs (Tu et al., 1999) and may be the cause of the perisynaptic localization of mGluR5 in the LA (in this study) and the hippocampus (Lujan et al., 1996). This may also contribute to examples of glutamate receptor cross talk for which the physical proximity of molecules may be important (Aniksztejn et al., 1991; Ben-Ari et al., 1992; Otani and Connor, 1998).

The involvement of mGluRs in hippocampal LTP is controversial and seems to depend on the strength of the induction protocol used, the history of synaptic plasticity of the cell, as well as the overall level of internal $\mathrm{Ca}^{2+}$ (Little et al., 1995; Wilsch et al., 1998; Bortolotto et al., 1999). Although no studies have specifically addressed the role of mGluRs in LTP induction in the LA, it is known that mGluRs can contribute to transmission in the basal nucleus of the amygdala (Rainnie et al., 1994). Our electrophysiological results show that MPEP blocks the induction of LTP in the LA with a tetanus protocol. This type of stimulation relies mainly on NMDARs for LTP induction (Huang and Kandel, 1998; Blair et al., 2001; Bauer et al., 2002) and was thus chosen to address the influence of mGluR5 on NMDARdependent LTP in the LA. The block of LTP by MPEP was most robust $30 \mathrm{~min}$ after tetanus, suggesting that mGluR5 may be involved in the initiation of downstream second messenger pathways and a modulation of NMDAR activity, as opposed to the alteration of simple ionic gating. Because baseline transmission was not affected by MPEP, it is likely that the LTP blockade is caused by the inhibition of the increase of intracellular $\mathrm{Ca}^{2+}$ and the activation of intracellular events that allow for synaptic strengthening.

Previous studies have shown that systemic administration of mGluR5 antagonists impairs fear conditioning as measured with the fear-potentiated startle paradigm (Schulz et al., 2001). In the present study, we gave rats intra-LA inf usions of MPEP to assess the involvement of mGluRs in the LA in auditory and contextual fear conditioning. The findings indicated that mGluR5 is critical for the acquisition of fear memories, as illustrated by a significant decrease in freezing behavior in rats given pretraining infusions. The fact that this impairment was evident at both 1 and $24 \mathrm{hr}$ after training implies that MPEP blocked a fast cascade of events necessary for fear learning and STM. Furthermore, the failure of MPEP to influence the expression of fear memories implicates mGluR5 function in the learning, but not the retrieval, of fear memories and also rules out potential nonspecific effects of MPEP on sensory processing at the time of training. These findings are in agreement with the electrophysiological data, which show that MPEP impairs LTP but not baseline transmission, and with recent data that show that systemic administration of MPEP has no effect on the expression of fear-potentiated startle (Schulz et al., 2001). Furthermore, post-training infusions of MPEP failed to affect either STM or LTM, which implies that mGluR5 is key for the acquisition, but not the consolidation, of fear conditioning. These findings complement those of previous studies that have demonstrated a role for NMDARs in fear acquisition and STM formation in the conditioning (Miserendino et al., 1990; Campeau et al., 1992; Fanselow and Kim, 1994; Lee and Kim, 1998; Walker and Davis, 2000; Rodrigues et al., 2001), raising the possibility that mGluR5 might contribute to fear memory formation in the LA via its close interaction with NMDARs.

The evidence of impaired acquisition and STM of fear condi- 
A.

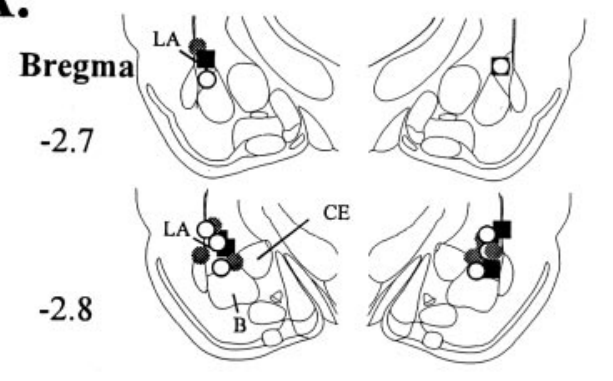

$-3.3$
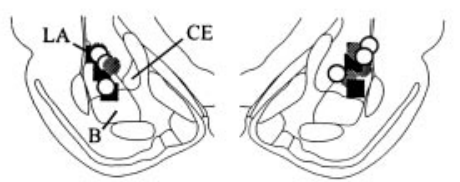

$-3.8$
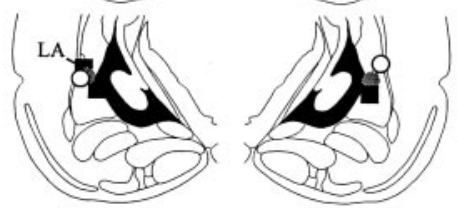

B.
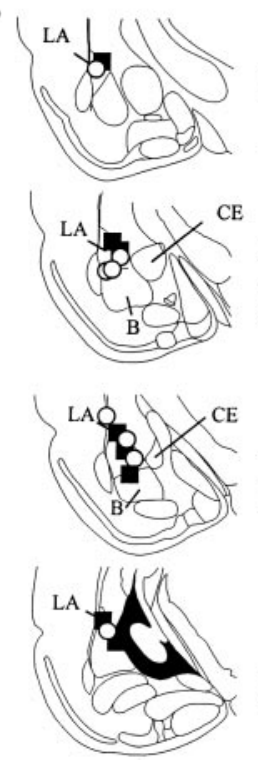
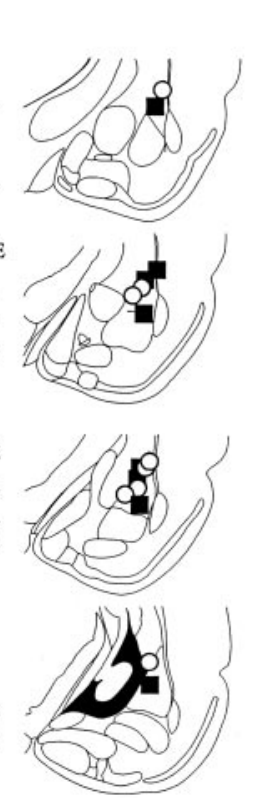

C.
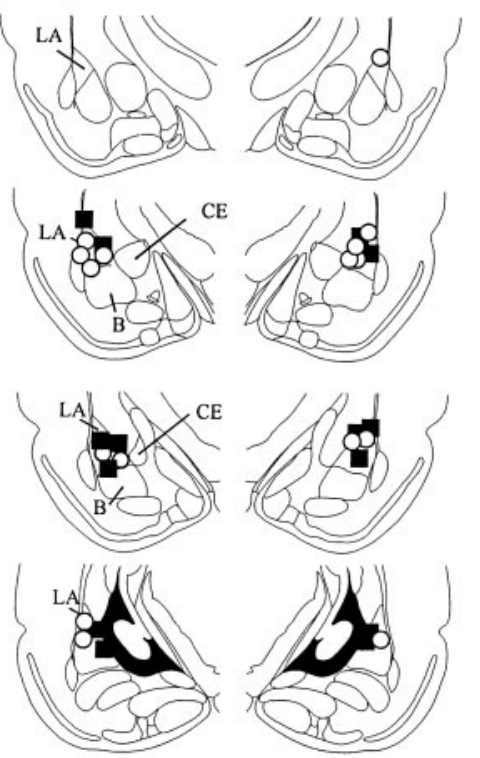

Figure 5. Cannula placements. A, Cannula tip placements from rats infused with vehicle (black squares), $0.15 \mu \mathrm{g}$ MPEP ( gray circles), or $1.5 \mu \mathrm{g}$ MPEP (white circles) before training. $B$, Cannula tip placements from rats in infused with vehicle (black squares) or $1.5 \mu \mathrm{g}$ MPEP (white circles) before testing. $C$, Cannula tip placements from rats infused with vehicle (black squares) or $1.5 \mu \mathrm{g}$ MPEP (white circles) immediately after training.

tioning in our experiments is consistent with that of other studies that show mGluR5 to be linked to fast $\mathrm{Ca}^{2+}$ - and second messenger-mediated activity at postsynaptic locations. Both mGluR1 and mGluR5, for example, are positively coupled to phospholipase $\mathrm{C}$, activation of which leads to the production of inositol 1,4,5-trisphosphate and diacylglycerol. These products are required for the release of $\mathrm{Ca}^{2+}$ from intracellular stores and the stimulation of protein kinase C (PKC) (Nakanishi, 1994). $\mathrm{PKC}$, in turn, is involved in various functions, including the induction of LTP and learning (Kennedy and Marder, 1992). Importantly, PKC is involved in the modulation of both mGluR5 and NMDAR activity (Anwyl, 1999; Alagarsamy et al., 2001; De Blasi et al., 2001). In addition, mGluR5 in astrocytes has been shown to induce $\mathrm{Ca}^{2+}$ oscillations via $\mathrm{PKC}$ phosphorylation (Nakahara et al., 1997; Nakanishi et al., 1998), which represents a glutamate-mediated bidirectional communication between neurons and astrocytes that is important for plasticity (Pasti et al., 1997). In behavioral studies, transgenic mice lacking the $\beta$ isoform of PKC have been shown to have a deficit in both auditory (white noise) and contextual fear conditioning (Weeber et al., 2000). In addition, PKC inhibition has been shown to block the acquisition, but not consolidation and retrieval, of conditioned taste aversion (Sacchetti and Bielavska, 1998). The role of amygdala PKCs in the acquisition and STM formation of fear conditioning has not been established and is an important question for future studies.

In conclusion, mGluR5 appears to play a sophisticated role in a wide variety of neural functions, including learning, memory, and plasticity. This can be attributed to its close association with NMDARs and $\mathrm{Ca}^{2+}$-mediated activities and its localization to postsynaptic sites. Our neuroanatomical, behavioral, and electrophysiological findings show that mGluR5 plays a key role in LTP and fear memory formation in the LA, possibly via its linkage to NMDAR-mediated plastic changes at postsynaptic sites.

\section{REFERENCES}

Alagarsamy S, Marino MJ, Rouse ST, Gereau RW, Heinemann SF, Conn PJ (1999) Activation of NMDA receptors reverses desensitization of mGluR5 in native and recombinant systems. Nat Neurosci 2:234-240.

Alagarsamy S, Sorensen SD, Conn PJ (2001) Coordinate regulation of metabotropic glutamate receptors. Curr Opin Neurobiol 11:357-362.

Ango F, Pin JP, Tu JC, Xiao B, Worley PF, Bockaert J, Fagni L (2000) Dendritic and axonal targeting of type 5 metabotropic glutamate receptor is regulated by homer1 proteins and neuronal excitation. J Neurosci 20:8710-8716.

Aniksztejn L, Bregestovski P, Ben-Ari Y (1991) Selective activation of quisqualate metabotropic receptor potentiates NMDA but not AMPA responses. Eur J Pharmacol 205:327-328.

Anwyl R (1999) Metabotropic glutamate receptors: electrophysiological properties and role in plasticity. Brain Res Brain Res Rev 29:83-120.

Balazs R, Miller S, Romano C, de Vries A, Chun Y, Cotman CW (1997) Metabotropic glutamate receptor mGluR5 in astrocytes: pharmacological properties and agonist regulation. J Neurochem 69:151-163.

Balschun D, Manahan-Vaughan D, Wagner T, Behnisch T, Reymann KG, Wetzel W (1999) A specific role for group I mGluRs in hippocampal LTP and hippocampus-dependent spatial learning. Learn Mem 6:138-152.

Bashir ZI, Bortolotto ZA, Davies CH, Berretta N, Irving AJ, Seal AJ, Henley JM, Jane DE, Watkins JC, Collingridge GL (1993) Induction of LTP in the hippocampus needs synaptic activation of glutamate metabotropic receptors. Nature 363:347-350.

Bauer EP, Schafe GE, LeDoux JE (2002) $N$-methyl-D-aspartate receptors and L-type voltage-gated calcium channels contribute to long-term potentiation and different components of fear memory formation in the lateral amygdala. J Neurosci, in press.

Ben-Ari Y, Aniksztejn L, Bregestovski P (1992) Protein kinase C modulation of NMDA currents: an important link for LTP induction. Trends Neurosci 15:333-339.

Blair HT, Schafe GE, Bauer EP, Rodrigues SM, LeDoux JE (2001) Synaptic plasticity in the lateral amygdala: a cellular hypothesis of fear conditioning. Learn Mem 8:229-242.

Bortolotto ZA, Fitzjohn SM, Collingridge GL (1999) Roles of metabotropic glutamate receptors in LTP and LTD in the hippocampus. Curr Opin Neurobiol 9:299-304.

Brakeman PR, Lanahan AA, O'Brien R, Roche K, Barnes CA, Huganir RL, Worley PF (1997) Homer: a protein that selectively binds metabotropic glutamate receptors. Nature 386:284-288.

Campeau S, Miserendino MJ, Davis M (1992) Intra-amygdala infusion of the $N$-methyl-D-aspartate receptor antagonist AP5 blocks acquisition but not expression of fear-potentiated startle to an auditory conditioned stimulus. Behav Neurosci 106:569-574.

De Blasi A, Conn PJ, Pin J, Nicoletti F (2001) Molecular determinants 
of metabotropic glutamate receptor signaling. Trends Pharmacol Sci 22:114-120.

Doherty AJ, Palmer MJ, Henley JM, Collingridge GL, Jane DE (1997) (RS)-2-chloro-5-hydroxyphenylglycine (CHPG) activates mGlu5, but no mGlu1, receptors expressed in $\mathrm{CHO}$ cells and potentiates NMDA responses in the hippocampus. Neuropharmacology 36:265-267.

Ehlers MD (1999) Synapse structure: glutamate receptors connected by the shanks. Curr Biol 9:R848-850.

Fanselow MS, Kim JJ (1994) Acquisition of contextual Pavlovian fear conditioning is blocked by application of an NMDA receptor antagonist D,L-2-amino-5-phosphonovaleric acid to the basolateral amygdala. Behav Neurosci 108:210-212.

Farb CR, LeDoux JE (1997) NMDA and AMPA receptors in the lateral nucleus of the amygdala are postsynaptic to auditory thalamic afferents. Synapse 27:106-121.

Farb CR, Aoki C, Ledoux JE (1995) Differential localization of NMDA and AMPA receptor subunits in the lateral and basal nuclei of the amygdala: a light and electron microscopic study. J Comp Neurol 362:86-108.

Fendt M (2001) Injections of the NMDA receptor antagonist aminophosphonopentanoic acid into the lateral nucleus of the amygdala block the expression of fear-potentiated startle and freezing. J Neurosci 21:4111-4115.

Fitzjohn SM, Irving AJ, Palmer MJ, Harvey J, Lodge D, Collingridge GL (1996) Activation of group I mGluRs potentiates NMDA responses in rat hippocampal slices. Neurosci Lett 203:211-213.

Gasparini F, Lingenhohl K, Stoehr N, Flor PJ, Heinrich M, Vranesic I, Biollaz M, Allgeier H, Heckendorn R, Urwyler S, Varney MA, Johnson EC, Hess SD, Rao SP, Sacaan AI, Santori EM, Velicelebi G, Kuhn R (1999) 2-Methyl-6-(phenylethynyl)-pyridine (MPEP), a potent, selective and systemically active mGlu5 receptor antagonist. Neuropharmacology 38:1493-1503.

Gewirtz JC, Davis M (1997) Second-order fear conditioning prevented by blocking NMDA receptors in amygdala. Nature 388:471-474.

Huang YY, Kandel ER (1998) Postsynaptic induction and PKAdependent expression of LTP in the lateral amygdala. Neuron 21:169-178.

Huber KM, Sawtell NB, Bear MF (1998) Effects of the metabotropic glutamate receptor antagonist $\mathrm{MCPG}$ on phosphoinositide turnover and synaptic plasticity in visual cortex. J Neurosci 18:1-9.

Hubert GW, Paquet M, Smith Y (2001) Differential subcellular localization of mGluR1a and mGluR5 in the rat and monkey substantia nigra. J Neurosci 21:1838-1847.

Jia Z Lu Y, Henderson J, Taverna F, Romano C, Abramow-Newerly W, Wojtowicz JM, Roder J (1998) Selective abolition of the NMDA component of long-term potentiation in mice lacking mGluR5. Learn Mem 5:331-343.

Kato A, Ozawa F, Saitoh Y, Hirai K, Inokuchi K (1997) vesl, a gene encoding VASP/Ena family related protein, is upregulated during seizure, long-term potentiation and synaptogenesis. FEBS Lett 412:183-189.

Kennedy MB, Marder E (1992) Cellular and molecular mechanisms of neuronal plasticity. In: An introduction to molecular neurobiology (Hall ZW, ed), pp 463-495. Sunderland, MA: Sinauer.

Kleppisch T, Voigt V, Allmann R, Offermanns S (2001) G $\alpha$ q-deficient mice lack metabotropic glutamate receptor-dependent long-term depression but show normal long-term potentiation in the hippocampal CA1 region. J Neurosci 21:4943-4948.

LeDoux JE (2000) Emotion circuits in the brain. Annu Rev Neurosci 23:155-184

LeDoux JE, Farb CF, Ruggiero DA (1990) Topographic organization of neurons in the acoustic thalamus that project to the amygdala. J Neurosci 10:1043-1054.

Lee H, Kim JJ (1998) Amygdalar NMDA receptors are critical for new fear learning in previously fear-conditioned rats. $\mathrm{J}$ Neurosci 18:8444-8454.

Little Z, Grover LM, Teyler TJ (1995) Metabotropic glutamate receptor antagonist, $(R, S)$-alpha-methyl-4-carboxyphenylglycine, blocks two distinct forms of long-term potentiation in area CA1 of rat hippocampus. Neurosci Lett 201:73-76.

Lu YM, Jia Z, Janus C, Henderson JT, Gerlai R, Wojtowicz JM, Roder JC (1997) Mice lacking metabotropic glutamate receptor 5 show impaired learning and reduced CA1 long-term potentiation (LTP) but normal CA3 LTP. J Neurosci 17:5196-5205.

Lujan R, Nusser Z, Roberts JD, Shigemoto R, Somogyi P (1996) Perisynaptic location of metabotropic glutamate receptors mGluR1 and mGluR5 on dendrites and dendritic spines in the rat hippocampus. Eur J Neurosci 8:1488-1500.

Mahanty NK, Sah P (1998) Calcium-permeable AMPA receptors mediate long-term potentiation in interneurons in the amygdala. Nature 394:683-687.

Mannaioni G, Marino MJ, Valenti O, Traynelis SF, Conn PJ (2001) Metabotropic glutamate receptors 1 and 5 differentially regulate CA1 pyramidal cell function. J Neurosci 21:5925-5934.
Maren S (2001) Neurobiology of Pavlovian fear conditioning. Annu Rev Neurosci 24:897-931.

Maren S, Holt W (2000) The hippocampus and contextual memory retrieval in Pavlovian conditioning. Behav Brain Res 110:97-108.

McDonald AJ (1992) Cell types and intrinsic connections of the amygdala. In: The amygdala: neurobiological aspects of emotion, memory, and mental dysfunction (Aggleton JP, ed), pp 67-96. New York: Wiley.

McGaugh JL (2000) Memory - a century of consolidation. Science 287:248-251.

Miserendino MJ, Sananes CB, Melia KR, Davis M (1990) Blocking of acquisition but not expression of conditioned fear-potentiated startle by NMDA antagonists in the amygdala. Nature 345:716-718.

Morris RG, Davis S, Butcher SP (1990) Hippocampal synaptic plasticity and NMDA receptors: a role in information storage? Philos Trans $\mathrm{R}$ Soc Lond B Biol Sci 329:187-204.

Naisbitt S, Kim E, Tu JC, Xiao B, Sala C, Valtschanoff J, Weinberg RJ, Worley PF, Sheng M (1999) Shank, a novel family of postsynaptic density proteins that binds to the NMDA receptor/PSD-95/GKAP complex and cortactin. Neuron 23:569-582.

Nakahara K, Okada M, Nakanishi S (1997) The metabotropic glutamate receptor mGluR5 induces calcium oscillations in cultured astrocytes via protein kinase C phosphorylation. J Neurochem 69:1467-1475.

Nakanishi S (1992) Molecular diversity of glutamate receptors and implications for brain function. Science 258:597-603.

Nakanishi S (1994) Metabotropic glutamate receptors: synaptic transmission, modulation, and plasticity. Neuron 13:1031-1037.

Nakanishi S, Nakajima Y, Masu M, Ueda Y, Nakahara K, Watanabe D, Yamaguchi S, Kawabata S, Okada M (1998) Glutamate receptors: brain function and signal transduction. Brain Res Brain Res Rev 26:230-235.

Negyessy L, Vidnyanszky Z, Kuhn R, Knopfel T, Gorcs TJ, Hamori J (1997) Light and electron microscopic demonstration of mGluR5 metabotropic glutamate receptor immunoreactive neuronal elements in the rat cerebellar cortex. J Comp Neurol 385:641-650.

O'Leary DM, Movsesyan V, Vicini S, Faden AI (2000) Selective mGluR5 antagonists MPEP and SIB-1893 decrease NMDA or glutamate-mediated neuronal toxicity through actions that reflect NMDA receptor antagonism. Br J Pharmacol 131:1429-1437.

Otani S, Connor JA (1998) Requirement of rapid $\mathrm{Ca}^{2+}$ entry and synaptic activation of metabotropic glutamate receptors for the induction of long-term depression in adult rat hippocampus. J Physiol (Lond) 511:761-770.

Paré D, Collins DR (2000) Neuronal correlates of fear in the lateral amygdala: multiple extracellular recordings in conscious cats. J Neurosci 20:2701-2710.

Paré D, Pape HC, Dong J (1995) Bursting and oscillating neurons of the cat basolateral amygdaloid complex in vivo: electrophysiological properties and morphological features. J Neurophysiol 74:1179-1191.

Pasti L, Volterra A, Pozzan T, Carmignoto G (1997) Intracellular calcium oscillations in astrocytes: a highly plastic, bidirectional form of communication between neurons and astrocytes in situ. J Neurosci 17:7817-7830.

Peters A, Josephson K, Vincent SL (1991) Effects of aging on the neuroglial cells and pericytes within area 17 of the rhesus monkey cerebral cortex. Anat Rec 229:384-398.

Phillips RG, LeDoux JE (1994) Lesions of the dorsal hippocampal formation interfere with background but not foreground contextual fear conditioning. Learn Mem 1:34-44.

Pin JP, Duvoisin R (1995) The metabotropic glutamate receptors: structure and functions. Neuropharmacology 34:1-26.

Pisani A, Gubellini P, Bonsi P, Conquet F, Picconi B, Centonze D Bernardi G, Calabresi P (2001) Metabotropic glutamate receptor 5 mediates the potentiation of $N$-methyl-D-aspartate responses in medium spiny striatal neurons. Neuroscience 106:579-587.

Quirk GJ, Repa C, LeDoux JE (1995) Fear conditioning enhances shortlatency auditory responses of lateral amygdala neurons: parallel recordings in the freely behaving rat. Neuron 15:1029-1039.

Rainnie DG, Asprodini EK, Shinnick-Gallagher P (1991) Excitatory transmission in the basolateral amygdala. J Neurophysiol 66:986-998.

Rainnie DG, Holmes KH, Shinnick-Gallagher P (1994) Activation of postsynaptic metabotropic glutamate receptors by trans-ACPD hyperpolarizes neurons of the basolateral amygdala. $\mathrm{J}$ Neurosci 14:7208-7220.

Repa JC, Muller J, Apergis J, Desrochers TM, Zhou Y, LeDoux JE (2001) Two different lateral amygdala cell populations contribute to the initiation and storage of memory. Nat Neurosci 4:724-731.

Riedel G, Casabona G, Platt B, Macphail EM, Nicoletti F (2000) Fear conditioning-induced time- and subregion-specific increase in expression of mGlu5 receptor protein in rat hippocampus. Neuropharmacology 39:1943-1951.

Rodrigues SM, Schafe GE, LeDoux JE (2001) Intra-amygdala blockade of the NR2B subunit of the NMDA receptor disrupts the acquisition but not the expression of fear conditioning. J Neurosci 21:6889-6896.

Rogan MT, LeDoux JE (1995) LTP is accompanied by commensurate 
enhancement of auditory-evoked responses in a fear conditioning circuit. Neuron 15:127-136.

Romano C, Sesma MA, McDonald CT, O’Malley K, Van den Pol AN, Olney JW (1995) Distribution of metabotropic glutamate receptor mGluR5 immunoreactivity in rat brain. J Comp Neurol 355:455-469.

Romanski LM, Clugnet MC, Bordi F, LeDoux JE (1993) Somatosensory and auditory convergence in the lateral nucleus of the amygdala. Behav Neurosci 107:444-450.

Sacchetti B, Bielavska E (1998) Chelerythrine, a specific PKC inhibitor, blocks acquisition but not consolidation and retrieval of conditioned taste aversion in rat. Brain Res 799:84-90.

Salt TE, Binns KE (2000) Contributions of mGlu1 and mGlu5 receptors to interactions with $N$-methyl-D-aspartate receptor-mediated responses and nociceptive sensory responses of rat thalamic neurons. Neuroscience 100:375-380.

Schoepp DD, Conn PJ (1993) Metabotropic glutamate receptors in brain function and pathology. Trends Pharmacol Sci 14:13-20.

Schulz B, Fendt M, Gasparini F, Lingenhohl K, Kuhn R, Koch M (2001) The metabotropic glutamate receptor antagonist 2-methyl-6(phenylethynyl)-pyridine (MPEP) blocks fear conditioning in rats. Neuropharmacology 41:1-7.

Shigemoto R, Kinoshita A, Wada E, Nomura S, Ohishi H, Takada M, Flor PJ, Neki A, Abe T, Nakanishi S, Mizuno N (1997) Differential presynaptic localization of metabotropic glutamate receptor subtypes in the rat hippocampus. J Neurosci 17:7503-7522.

Tsien JZ, Huerta PT, Tonegawa S (1996) The essential role of hip- pocampal CA1 NMDA receptor-dependent synaptic plasticity in spatial memory. Cell 87:1147-1148.

Tu JC, Xiao B, Naisbitt S, Yuan JP, Petralia RS, Brakeman P, Doan A, Aakalu VK, Lanahan AA, Sheng M, Worley PF (1999) Coupling of mGluR/Homer and PSD-95 complexes by the Shank family of postsynaptic density proteins. Neuron 23:583-592.

Walker DL, Davis M (2000) Involvement of NMDA receptors within the amygdala in short- versus long-term memory for fear conditioning as assessed with fear-potentiated startle. Behav Neurosci 114:1019-1033.

Weeber EJ, Atkins CM, Selcher JC, Varga AW, Mirnikjoo B, Paylor R, Leitges M, Sweatt JD (2000) A role for the beta isoform of protein kinase C in fear conditioning. J Neurosci 20:5906-5914.

Weisskopf MG, LeDoux JE (1999) Distinct populations of NMDA receptors at subcortical and cortical inputs to principal cells of the lateral amygdala. J Neurophysiol 81:930-934.

Weisskopf MG, Bauer EP, LeDoux JE (1999) L-type voltage-gated calcium channels mediate NMDA-independent associative long-term potentiation at thalamic input synapses to the amygdala. J Neurosci 19:10512-10519.

Wilsch VW, Behnisch T, Jager T, Reymann KG, Balschun D (1998) When are class I metabotropic glutamate receptors necessary for longterm potentiation? J Neurosci 18:6071-6080.

Yu SP, Sensi SL, Canzoniero LM, Buisson A, Choi DW (1997) Membrane-delimited modulation of NMDA currents by metabotropic glutamate receptor subtypes $1 / 5$ in cultured mouse cortical neurons. J Physiol (Lond) 499:721-732. 